\title{
Clinical Performances of Pure TB-Lamp Kit for M. tuberculosis Complex Detection in Sputum Samples
}

\author{
Kouassi N'guessan ${ }^{*}$, Jacob Adegbele1, Ibrahima Coulibaly², Natacha Kouame-N'takpé2, \\ Hortense Seck-Angu1, André Guei ${ }^{1}$, Jacquemin Kouakou ${ }^{3}$, Mireille Dosso ${ }^{1}$ \\ ${ }^{1}$ Laboratoire Nationale de Référence de la Tuberculose, Institut Pasteur de Côte d'Ivoire, Abidjan, Côte d'Ivoire \\ ${ }^{2}$ Centre Antituberculeux de Yopougon, Abidjan, Côte d'Ivoire \\ ${ }^{3}$ Programme National de Lutte contre la Tuberculose, Abidjan, Côte d’Ivoire \\ Email: *ngueskr@yahoo.fr
}

How to cite this paper: N'guessan, K., Adegbele, J., Coulibaly, I., KouameN’takpé, N., Seck-Angu, H., Guei, A., Kouakou, J. and Dosso, M. (2017) Clinical Performances of Pure TB-Lamp Kit for $M$. tuberculosis Complex Detection in Sputum Samples. Journal of Tuberculosis Research, 5, 129-138.

https://doi.org/10.4236/jtr.2017.52014

Received: May 7, 2017

Accepted: June 16, 2017

Published: June 19, 2017

Copyright $\odot 2017$ by authors and Scientific Research Publishing Inc. This work is licensed under the Creative Commons Attribution International License (CC BY 4.0).

http://creativecommons.org/licenses/by/4.0/

\section{(c) (i) Open Access}

\begin{abstract}
Tuberculosis represents a main concern for public health worldwide. In poor countries, the most prevalent method for bacteriological confirmation remains Smear Sputum Microscopy (SSM). This study objective was to assess clinical performances of Loop Mediated Isothermal Amplification for TB detection (Lamp-TB). Sputum of patients presenting symptoms consistent with tuberculosis were collected according to the National Tuberculosis Control Programme guidelines in Centre Antituberculeux de Yopougon. SSM after Ziehl-Neelsen staining and TB-Lamp were blindly performed with spot sputum specimen. Samples, transported at Institut Pasteur de Côte d'Ivoire were decontaminated according to $\mathrm{N}$-acetyl- ${ }_{\mathrm{L}}$-cystein (NALC) method. In Mycobacteria Growth Indicator Tube (MGIT), $500 \mu$ of pellet were inoculated and incubated in MGIT 960 instrument. MPT64 antigen was detected on positive culture. Of 500 patients enrolled, 469 were included. Clinical isolates of $M$. tuberculosis Complex were detected for 157 (33.5\%). Comparatively to culture, Sensitivity and Specificity of SSM were 86\% (95\% Confidence interval (CI): $81 \%$ - 91\%) 96\% (95\%IC: 94\% - 98\%) respectively. TB-Lamp Sensitivity was 92\% (95\%CI: 88\% - 96\%), and Specificity 94\% (95\%CI: 91\% - 97\%). Positive Predictive Value of SSM and TB-Lamp was $91.8 \%$ and $88.8 \%$ respectively. Negative Predictive Value of TB-Lamp assay was $95.7 \%$ whereas this of SSM was $93.3 \%$. Positive Likelihood Ratio was 15.3 for TB-Lamp and 21.5 for SSM 21.5 whereas negative Likelihood of TB-Lamp was lower than SSM. Active tuberculosis was detected in162/469 (34.5\%) with TB-Lamp and 147 (31.3\%) with SSM. TB-Lamp assay performances estimated from sputum samples may improve detection of active $\mathrm{TB}$ cases in routine.
\end{abstract}




\section{Keywords}

Tuberculosis, Ziehl-Neelsen, TB-Lamp Assay

\section{Introduction}

Tuberculosis (TB) remains an important global public health problem [1]. In fact, the lack of rapid and accurate diagnostic testing is an obstacle to global TB control.

In resource-poor countries, TB is endemic and the most prevalent tool for bacteriological confirmation is still sputum smear microscopy after Ziehl Neelsen or Auramin staining. In most cases, TB control relies on passive case finding among individuals self-presenting to health care facilities. If the Specificity of acid-fast microscopy is excellent for Mycobacterial species [2], its Sensitivity and Specificity for diagnosis of pulmonary tuberculosis depend on several factors [3] [4] [5].

Culture, while reliable, takes weeks to obtain results. It requires adapted infrastructures and laboratory staff well trained.

Identifying a tool reducing diagnostic process, facilitating early and accurate Tuberculosis diagnosis would be appreciated by patients and health caregivers.

Several methods have been developed of whom two are relatively easy to use and implement. They can be used at district and sub-district levels [6] [7] [8]. Its concerns GeneXpert MTB/RIF assay and loop-mediated isothermal amplification for M. tuberculosis Complex (TB-Lamp). This method is dependent on autocycling strand displacement DNA synthesis performed by the Bst DNA polymerase large fragment which has high-strand displacement activity, and is carried out at $65^{\circ} \mathrm{C}$ for 1 hour [9]. TB-Lamp assay seems well adapted for in low incomes countries [6] [10].

In this study, we compared performances of Sputum Smear Microscopy after Ziehl-Neelsen staining and TB-Lamp assay, two tools easy to implement in low incomes countries.

\section{Materials and Methods}

\subsection{Ethical Statement}

The study was approved by the Comité National d'éthique et de Recherche under the reference $\mathrm{N}^{\circ} 70 / \mathrm{MSLS} / \mathrm{CNER}-\mathrm{dkn}$.

This cross sectional study linked to a Request of Application (RFA) formulated by Foundation for Innovative New Diagnostics was conducted from 09 December 2013 to 13 June 2014 in Centre Antituberculeux (CAT) de Yopougon one of the 17 intermediate Tuberculosis centres in Côte d'Ivoire. It's located in the big commune of Yopougon in District of Abidjan. After one week of training at Douala (Cameroon) with Manufacturer staff (Eiken Chemical Company Ltd, Tokyo, Japan) concerning use of PURE Lamp for Tuberculosis diagnosis, technicians 
trained have implemented the method in laboratory of CAT de Yopougon.

Laboratory of CAT de Yopougon is a room of $12 \mathrm{~m}^{2}$. It has been organized in different sections (sputum collection, smear preparation and staining, DNA extraction and heating block device provided by Eiken (Eiken Chemical Company Ltd, Tokyo, Japan) corresponding to each step of analysis performed.

In Côte d'Ivoire, 23.750 TB cases were notified in 2014 that represents an estimated incidence of 105/100.000 population [1]. Guidelines of National Tuberculosis Programme (NTP) recommend two sputum samples (Spot-Morning) separated from 24 hours at least for pulmonary tuberculose passive case detection. Main method used for Tuberculosis confirmation is SSM sputum smear microscopy after Ziehl-Neelsen or Auramin staining. An active Tuberculosis case is notified, if Acid Fast Bacilli are detected in one of samples collected.

\subsection{Patients and Clinical Specimens Enrollment}

Health workers in tuberculose centre screened patients based on their medical history. Two sputum samples (Spot-Morning) were collected to patients presenting a cough since at least 2 weeks ago. With Spot sputum collected, SSM after ZiehlNeelsen staining and TB-Lamp were blindly performed respectively.

Five hundred microliters of sputum were used for direct examination after Ziehl-Neelsen staining. A molecular test for $M$. tuberculosis Complex clinical strains detection was performed with the same sample, Sputum was well mixed by lightly shock of container on work plan. With a pipet provided by manufacturer (Eiken Chemical Company Ltd, Tokyo, Japan) $40 \mathrm{ml}$ of sputum were transferred in heating tube (Eiken Chemical Company Ltd, Tokyo, Japan). The tube inoculated was incubated at $90^{\circ}$ for 5 minutes. After incubation, heating tube was inserted to adsorbent tube and well mixed. Injection cap was inserted. By squeezing of adsorbant tube, $30 \mu$ of extracted DNA were transferred directly in reaction tube (Eiken Chemical Company Ltd, Tokyo, Japan). Reaction tube contained dried Lamp reaction mix (primers, dNTPs, buffer, Bst DNA polymerase). Mix reaction was reconstituated by inversion (five times) and incubated at $67^{\circ} \mathrm{C}$ for 40 minutes. Positive and negative control provided by manufacturer (Eiken Chemical Company Ltd, Tokyo, Japan) were included in each series of analysis. A positive TB-Lamptest for M. tuberculosis Complex strains was determined by visual detection of fluorescence light from the reaction tube using Ultra-Violet light (Figure 1).

Sputum samples collected were stored at $4^{\circ} \mathrm{C}$ during 1 to 5 days and transported at $4^{\circ} \mathrm{C}$ in ice box to National Tuberculosis Reference Laboratory situated at Institut Pasteur Pasteur de Côte d'Ivoire.

\subsection{National Tuberculosis Reference Laboratory}

Manipulations of infectious clinical specimens were performed in Class II safety cabinet (The Baker Company, USA) in a BLS3 laboratory. The same sputum used for SSM and TB-Lamp assay was decontaminated with $\mathrm{N}$-acetyl- ${ }_{-}-$Cystein, $4 \% \mathrm{NaoH}-2.9 \%$ Citrate (final concentration of $\mathrm{NAOH} 1 \%$ ), following by an 


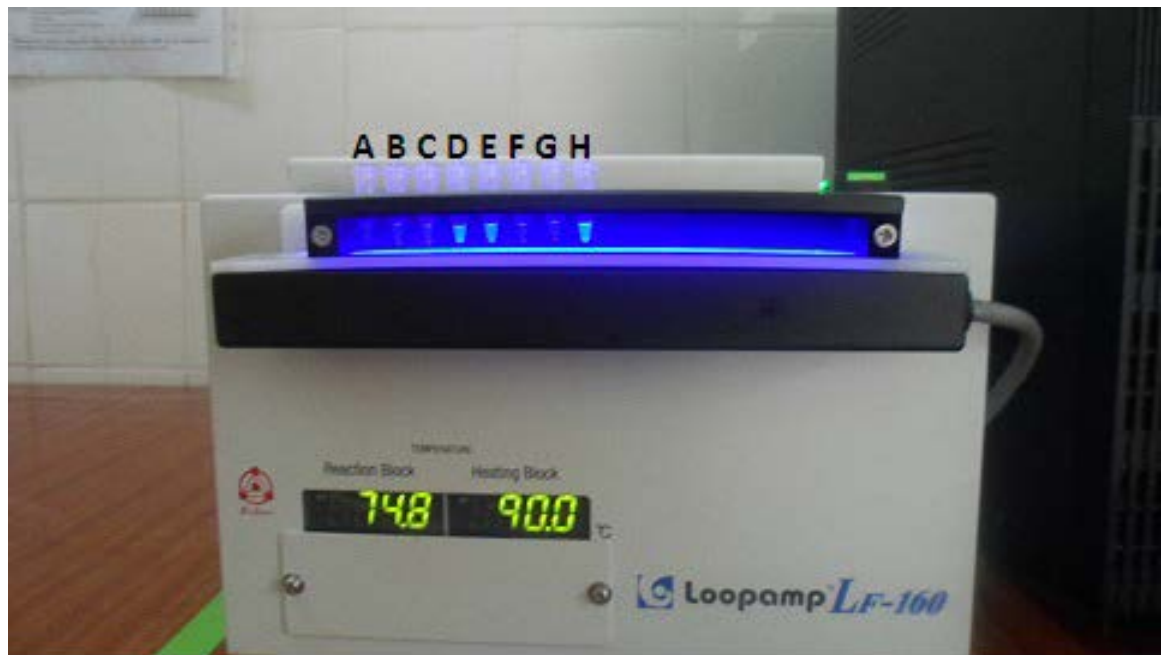

Samples A, B, C and F: fluorescence not detected (M. tuberculosis strains not detected); Samples D and E: fluorescence detected (M. tuberculosis strains detected); G: fluorescence not detected in Negative control tube; $\mathrm{H}$ : fluorescence detected in Positive control tube.

Figure 1. Visual detection of fluorescence in reaction tube using UV light.

incubation period at room temperature of $15 \mathrm{~min}$. Sputum samples were centrifuged at $3.000 \mathrm{~g}$ for $20 \mathrm{~min}$. Supernatant of concentrated sputum were carefully eliminated. Pellet was resuspended with $2 \mathrm{ml}$ of sterile phosphate buffer.

Five hundred microliters of suspension were inoculated in Mycobacteria Growth Indicator Tube (MGIT) containing oleic acid albumin, dextrose, and catalase (OADC)(Becton-Diagnostics, Dickinson, USA). Tubes inoculated were incubated at $37^{\circ} \mathrm{C}$ in MGIT 960 instrument (BD, Biosciences, Sparks, Maryland, USA). Positive cultures were examined for Acid Fast Bacilli (AFB) detection using Ziehl-Neelsen staining. Detection of antigen MPT64 in accordance with the manufacturer procedure (Standard Diagnostics, Seoul, South Korea) was done for identification of Mycobacterium tuberculosis Complex strain.

\section{Statistical Analysis}

Sensitivity, Specificity, Positive and Negative Predictive Value, Positive and negative Likelihood Ratio of SSM after Ziehl-Neelsen staining and TB-Lamp assay were determined using liquid culture as Gold Standard.

\section{Results}

Five hundred patients with signs and symptoms consistent with TB, and having consent form signed, were enrolled. One sputum sample of each patient (Spot) was put in culture. Among the 500 recruited, cultures in MGIT liquid medium of $31(6.2 \%)$ were contaminated. In total, 469 patients were included among which 232 (49.5\%) were male and 237 (50.5\%) female. The age class comprised between 25 and 34 was the most represented with an effective of 148 symptomatic patients. The mean of age for male was 36.9 years, the youngest and oldest were 15 and 86 years-old. In female group, youngest and oldest were respectively 15 and 85 years-old with mean age of 37.3 years. Among patients included, 56 
(11.9\%) were infected with HIV of whom 42 female (Table 1).

Of 469 smears prepared 147 (31.3\%) were positive for AFB detection of which 6 were interpreted as scanty. Culture and Pure TB-Lamp assay permitted to identify 157 (33.5\%) and 162 (34.5\%) M. tuberculosis clinical strains (Table 2). Total number of negative culture was 312 after 42 days of incubation in MGIT 960 instrument (Table 4).

Of the 56 patients infected with HIV, an active TB was confirmed for 53 (94.6\%) of whom 12 and 44 respectively with negative and positive smears. Concerning patients with negative smears, 9 clinical strains of $M$. tuberculosis was detected in sputum of which 7 with TB-Lamp and 2 with TB AgMPT64 rapid test. With 44 positive smears, TB-Lamp assay and culture results were concordant for 39 sputum samples (M. tuberculosis strains identified). For 5 specimens discrepancies results were observed of which 4 for TB-Lamp assay 4 and 1 for immunochromatographic assay (Table 3 ).

Comparatively to culture, Sensitivity and Specificity of SSM were $86 \%$ (95\% IC: 81 - 91) 96\% (95\% IC: 94 - 98) respectively. TB-Lamp assay Sensitivity was 92\% (95\% IC: 0.88 - 0.96), and Specificity 94\%; IC 95\%: [0.91 - 0.97]. Positive Predictive Value of SSM and TB-Lamp was $91.8 \%$ and $88.8 \%$ respectively (Table 4).

Among the 22 sputum samples (Positive culture and negative for SSM) 11 were respectively positive for TB-Lamp assay. The 11 others, were found again 13 sputum samples (Positive culture and Negative TB-Lamp) excepted 2 (Table 4). Of the 12 sputum (Negative culture and positive for SSM) 10 were positive with TB-Lamp assay. Of the 18 samples (Negative culture and Positive TBLamp), 10 samples (Negative culture and positive for SSM) were found again among the 12 (Negative culture and positive for SSM). The remaining 8 sputum samples were negative for AFB detection (Table 4).

Positive Likelihood ratio was 15.3 for TB-Lamp and 21.5 for SSM whereas negative Likelihood of TB-Lamp was lower than of SSM (0.09 versus 0.15) (Table 4).

\section{Discussion}

Social impact of Tuberculosis represents a high burden on the way of development. This communicable disease requires an accurate diagnosis with performant tool easy to implement particularly in poor countries.

M. tuberculosis clinical isolates was detected in 157 sputum samples with culture in liquid media (Gold standard) and 162 with TB-Lamp assay. Positive SSM was obtained for 147 sputum samples (Table 2).

Clinical performances of SSM and TB-Lamp kit determined with Spot sputum specimen showed that Sensitivity of SSM (86\%) was lower than TB-Lamp assay (92\%). Whereas the Specificity of SSM 96\% was higher than TB-Lamp assay (96\% versus 92\%).

Concerning Sensitivity of methods used, of the 157 M. tuberculosis clinical strains detected, 22 and 13 were missed by SSM and TB-Lamp assay respectively. 
Table 1. Patients included informations.

\begin{tabular}{|c|c|c|}
\hline items & Male $(n=232)$ & Female $(\mathrm{n}=237)$ \\
\hline & 36.9 & 37.3 \\
\hline Mean of age (years) & $\begin{array}{l}\text { minimum: } 15 \text { years-old } \\
\text { maximum: } 86 \text { years-old }\end{array}$ & $\begin{array}{l}\text { Minimum: } 15 \text { years-old } \\
\text { maximum: } 85 \text { years-old }\end{array}$ \\
\hline \multicolumn{3}{|l|}{ Age class } \\
\hline $15-24$ & 44 & 36 \\
\hline $25-34$ & 62 & 86 \\
\hline $35-44$ & 68 & 59 \\
\hline$\geq 45$ & 58 & 56 \\
\hline Infected with HIV+ & 14 & 42 \\
\hline \multicolumn{3}{|l|}{ Cough } \\
\hline$<2$ weeks & 82 & 82 \\
\hline$>2$ weeks & 150 & 155 \\
\hline \multicolumn{3}{|l|}{ With eight loss } \\
\hline Yes & 171 & 181 \\
\hline No & 61 & 56 \\
\hline \multicolumn{3}{|l|}{ Fever } \\
\hline Yes & 159 & 170 \\
\hline No & 73 & 67 \\
\hline \multicolumn{3}{|l|}{ Noctural sweat } \\
\hline Yes & 106 & 122 \\
\hline No & 126 & 115 \\
\hline \multicolumn{3}{|l|}{ Anorexia } \\
\hline Yes & 91 & 135 \\
\hline No & 141 & 102 \\
\hline \multicolumn{3}{|l|}{ Asthenia } \\
\hline Yes & 177 & 195 \\
\hline No & 55 & 42 \\
\hline
\end{tabular}

Table 2. Results of tools used for pulmonary TB diagnostic.

Sputum smears microscopy results Positive TB-Lamp $(n=162)$ Negative TB-Lamp $(n=307)$

\begin{tabular}{ccc}
\hline Scanty & 6 & - \\
$1+$ & 34 & 3 \\
$2+$ & 36 & - \\
$3+$ & 67 & 1 \\
Negative & 19 & 303 \\
\hline
\end{tabular}


Table 3. Patients infected with HIV results for tuberculosis.

\begin{tabular}{cccc}
\hline & TB-Lamp results & Positive MPT64 & Negative culture \\
\hline \multirow{2}{*}{ Positive smears $(\mathrm{n}=\mathbf{4 4})$} & Positive TB-Lamp & 39 & 4 \\
& Negative TB-Lamp & 1 & - \\
& Positive TB-Lamp & 3 & 4 \\
Negative smears $(\mathrm{n}=\mathbf{1 2})$ & Negative TB-Lamp & 2 & 3 \\
\hline
\end{tabular}

Table 4. Performances of tools used.

\begin{tabular}{|c|c|c|c|c|c|c|}
\hline & $\begin{array}{l}\text { Positive } \\
\text { culture }\end{array}$ & $\begin{array}{l}\text { Negative } \\
\text { culture }\end{array}$ & $\begin{array}{l}\text { Sensitivity and } \\
\text { Specificity }\end{array}$ & $\begin{array}{l}\text { Positive } \\
\text { likelihood } \\
\text { ratio }\end{array}$ & $\begin{array}{l}\text { Negative } \\
\text { likelihood } \\
\text { ratio }\end{array}$ & $\begin{array}{l}\text { Positive and } \\
\text { Negative pre- } \\
\text { dictive values }\end{array}$ \\
\hline SSM- & 135 & 300 & $\begin{array}{c}\text { Sensitivity: } 86 \% \\
\text { 95\% CI: }[81 \%-91 \%] \\
\text { Specificity: } 96 \% \\
95 \% \text { CI: }[94 \%-98 \%]\end{array}$ & 21.5 & 0.15 & $\begin{array}{l}\text { PPV: } 91.8 \% \\
\text { NPV: } 93.3 \%\end{array}$ \\
\hline LAMP-TB+ & 144 & 294 & $\begin{array}{c}\text { Sensitivity: 92\% } \\
\text { 95\% CI: }[88 \%-96 \%] \\
\text { Specificity: } 94 \% \\
\text { 95\% CI: }[91 \%-97 \%]\end{array}$ & 15.3 & 0.09 & $\begin{array}{l}\text { PPV: } 88.8 \% \\
\text { NPV: } 95.7 \%\end{array}$ \\
\hline
\end{tabular}

CI: Confidence Interval; PPV: Positive Predictive Value; NPV: Negative Predictive Value; SSM+: Sputum Smear Microscopy positive for Acid Fast Bacilli detection; SSM-: Sputum Smear Microscopy negative for Acid Fast Bacilli detection.

An analysis of results obtained by each method on the same sample showed that TB-Lamp detected 11 M. tuberculosis Complex clinical strains missed by SSM (Table 3 and Table 4). This study shows that for active tuberculosis detection in routine, Sensitivity of TB-Lamp assay is higher than SSM. Previous studies conducted in differents setting have demonstrated that TB-Lamp assay has an excellent sensitivity for Tuberculose detection [10]-[15].

Compared to TB-Lamp assay specificity, SSM specificity was higher than molecular method used. This represents one of the weakness of our study. We suggest a cross-contamination occured during smear microscopy examination process or an absence of sputum homogenization before transfer in pipet (TBLamp assay). We can also suggest an infection due to Non tuberculous Mycobacteria. Indeed 2 samples positive for AFB detection were negative after TB-Lamp testing showing that SSM is excellent for Mycobacteria species [2]. In this case we don't have lot of proofs because spot sputum sample was used for this study.

According to the Gold standard, discriminant power of TB-Lamp was higher than SSM for M. tuberculosis clinical isolates detection. The reason may be target of each method. Indeed, results showed that among 312 negative cultures, 8 negative smears were positive by TB-Lamp testing (Table 4).

Comparatively to SSM, performances of TB-Lamp assay obtained with sputum samples show that this molecular method could be used for detection of ac- 
tive TB case in routine [16]. Indeed TB-Lamp assay permitted to perform an accurate diagnosis of active TB cases for 162 patients presenting symptoms consistent with tuberculosis that represents 15 more cases than with SSM in spite of his higher Positive Predictive Value (Table 4).

Considering emergence of TB drug resistance, although utility of TB-Lamp assay for TB diagnosis is clearly established, it is unable to detect drug-resistant patterns notably surrogate marker of multi-drug resistance [17] [18] [19].

Considering results of the study, some steps of Mycobacteria culture process need to be improved particularly sputum sample quality, sputum conservation and transport [20].

\section{Conclusion}

For accurate diagnosis of active tuberculosis of patients presenting signs consistent with tuberculosis TB-Lamp assay is more performant than Sputum Smear Microscopy and does not require specific equipment.

\section{Acknowledgements}

We thank Eiken Chemical Company (Tokyo, Japan) for TB-Lamp kit and heating block provided. We also thank anonymous reviewers for their contributions.

\section{Funding Sources}

Foundation for Innovative New Diagnostics (FIND) supported this study.

\section{Authors' Contribution}

- Study concept and design: FIND and N'GUESSAN (clinical microbiologist)

- Statistical analysis: N'GUESSAN.

- Study supervision: ADEGBELE Jacobs (student), COULIBALI Ibrahim (Head of CAT of Yopougon).

- Bacteriological tests: KOUAME-N’TAKPE Natacha (Biotechnologist), GUEI André (Biotechnologist), SECK-ANGU H (Sanitary technical Enginer).

- Analyisis and interpretation: N'GUESSAN, Pr DOSSO Mireille (clinical microbiologist) and Dr. KOUAKOU Jacquemin (National Tuberculosis Programme Coordinator).

\section{Conflict of Interest}

The auhors declare no conflict of interest.

\section{References}

[1] World Health Organization (2015) Global Tuberculosis Report 2015, WHO/HTM/ $\mathrm{TB} / 2015$. 22. World Health Organization, Geneva, Switzerland.

[2] Somoskövi, A., Hotaling, J.E., Fitzgerald, M., O’Donnell, D., Parsons, L.M. and Salfinger, M. (2001) Lessons from a Proficiency Testing Event for Acid-Fast Microscopy. Chest, 120, 250-257. https://doi.org/10.1378/chest.120.1.250

[3] Shea, Y.R., Davis, J.L., Huang, L., Kovacs, J.A., Masur, H., Mulindwa, F., Opus, S., 
Chow, Y. and Murray, P.R. (2009) High Sensitivity and Specificity of Acid-Fast Microscopy for Diagnosis of Pulmonary Tuberculosis in an African Population with a High Prevalence of Human Immunodeficiency Virus. Journal of Clinical Microbiology, 47, 1553-1555. https://doi.org/10.1128/JCM.00348-09

[4] Steingart, K.R., Ramsay, A. and Pai, M. (2007) Optimizing Sputum Smear Microscopy for the Diagnosis of Pulmonary Tuberculosis. Expert Review of Anti-Infective Therapy, 5, 327-331. https://doi.org/10.1586/14787210.5.3.327

[5] Grosset, J. (1995) Place des examens microbiologiques et anatomopathologiques dans la décision diagnostique et thérapeutique. Médecine et Maladies Infectieuses, 25, 327-333. https://doi.org/10.1016/S0399-077X(05)80591-8

[6] Boehme, C.C., Nabeta, P., Henostroza, G., Raqib, R., Rahim, Z., Gerhardt, M., Sanga, E., Hoelscher, M., Notomi, T., Hase, T. and Perkins, M.D. (2007) Operational Feasibility of Using Loop-Mediated Isothermal Amplification for Diagnosis of Pulmonary Tuberculosis in Microscopy Centers of Developing Countries. Journal of Clinical Microbiology, 45, 1936-1940. https://doi.org/10.1128/JCM.02352-06

[7] World Health Organization (2013) Automated Real-Time Nucleic Acid Amplification Technology for Rapid and Simultaneous Detection of Tuberculosis and Rifampicin Resistance: Xpert MTB/RIF Assay for the Diagnosis of Pulmonary and Extrapulmonary TB in Adults and Children. WHO/HTM/TB/2013.16, World Health Organization, Geneva, Switzerland.

[8] Boehme, C.C., Nicol, M.P., Nabeta, P., Michael, J.S., Gotuzzo, E., Tahirli, R., Gler, M.T., Blakemore, R., Worodria, W., Gray, C., Huang, L., Caceres, T., Mehdiyev, R., Raymond, L., Whitelaw, A., Sagadevan, K., Alexander, H., Albert, H., Cobelens, F., Cox, H., Alland, D. and Perkins, M.D. (2011) Feasibility, Diagnostic Accuracy, and Effectiveness of Decentralised Use of the Xpert MTB/RIF Test for Diagnosis of Tuberculosis and Multidrug Resistance: A Multicentre Implementation Study. The Lancet, 377, 1495-1505. https://doi.org/10.1016/S0140-6736(11)60438-8

[9] Notomi, T., Okayama, H., Masubuchi, H., Yonekawa, T., Watanabe, K. and Amino, N. (2000) Hase T: Loop-Mediated Isothermal Amplification of DNA. Nucleic Acids Research, 28, e63. https://doi.org/10.1093/nar/28.12.e63

[10] Gray, C.M., Katamba, A., Narang, P., Giraldo, J., Zamudio, C., Joloba, M., Narang, R., Paramasivan, C.N., Hillemann, D., Nabeta, P., Amisano, D., Alland, D., Cobelens, F. and Boehme, C.C. (2016) Feasibility and Operational Performance of Tuberculosis Detection by Loop-Mediated Isothermal Amplification Platform in Decentralized Settings: Results from a Multicenter Study. Journal of Clinical Microbiology, 54, 1984-1991. https://doi.org/10.1128/JCM.03036-15

[11] Geojith, G., Dhanasekaran, S., Chandran, S.P. and Kenneth, J. (2011) Efficacy of Loop Mediated Isothermal Amplification (LAMP) Assay for the Laboratory Identification of Mycobacterium tuberculosis Isolates in a Resource Limited setting. Journal of Microbiological Methods, 84, 71-73. https://doi.org/10.1016/j.mimet.2010.10.015

[12] Ou, X., Li, Q., Xia, H., Pang, Y., Wang, S., Zhao, B., Song, Y., Zhou, Y., Zheng, Y., Zhang, Z., Zhang, Z., Li, J., Dong, H., Zhang, J., Kam, K.M., Chi, J., Huan, S., Chin, D.P. and Zhao, Y. (2011) Diagnostic Accuracy of the PURE-LAMP Test for Pulmonary Tuberculosis at the County-Level Laboratory in China. PLoS ONE, 9 , e94544.

[13] Khatib, S.I., Williamson, M.T., Singh, R. and Joshi, J.M. (2012) Diagnosis of Pulmonary Tuberculosis by Smear Microscopy and Culture in a Tertiary Health Care Facility. Biology and Medicine, 4, 32-36.

[14] Neonakis, I.K., Spandidos, D.A. and Petinaki, E. (2011) Use of Loop-Mediated Iso- 
thermal Amplification of DNA for the Rapid Detection of Mycobacterium tuberculosis in Clinical Specimens. European Journal of Clinical Microbiology \& Infectious Diseases, 30, 937-942.

[15] Mitarai, S., Okumura, M., Toyota, E., Yoshiyama, T., Aono, A., Sejimo, A., Azuma, Y., Sugahara, K., Nagasawa, T., Nagayama, N., Yamane, A., Yano, R., Kokuto, H., Morimoto, K., Ueyama, M., Kubota, M., Yi, R., Ogata, H., Kudoh, S. and Mori, T. (2011) Evaluation of a Simple Loop-Mediated Isothermal Amplification Test Kit for the Diagnosis of Tuberculosis. The International Journal of Tuberculosis and Lung Disease, 15, 1211-1217. https://doi.org/10.5588/ijtld.10.0629

[16] World Health Organization (2016) The Use of Loop-Mediated Isothermal Amplification (TB-LAMP) for the Diagnosis of Pulmonary Tuberculosis: Policy Guidance WHO/HTM/TB/2016.07. World Health Organization, Geneva, Switzerland.

[17] Rahman, A., Sahrin, M., Afrin, S., Earley, K., Ahmed, S., Mazidur Rahman, S.M. and Banu, S. (2016) Comparison of Xpert MTB/RIF Assay and GenoType MTBDRplus DNA Probes for Detection of Mutations Associated with Rifampicin Resistance in Mycobacterium tuberculosis. PLOS ONE, 11, e0152694. https://doi.org/10.1371/journal.pone.0152694

[18] Bojang, A.L., Mendy, F.S., Tientcheu, L.D., Otu, J., Antonio, M., Kampmann, B., Agbla, S. and Sutherland, J.S. (2016) Comparison of TB-LAMP, GeneXpert MTB/ RIF and Culture for Diagnosis of Pulmonary Tuberculosis in the Gambia. Journal of Infection, 72, 332-337. https://doi.org/10.1016/j.jinf.2015.11.011

[19] Mboowa, G., Namaganda, C. and Ssengooba, W. (2014) Rifampicin Resistance Mutations in the 81 bp RRDR of rpoB Gene in Mycobacterium tuberculosis Clinical Isolates Using Xpert ${ }^{\oplus} \mathrm{MTB} / \mathrm{RIF}$ in Kampala, Uganda: A Retrospective Study. BMC Infectious Diseases, 14, 481. https://doi.org/10.1186/1471-2334-14-481

[20] Parsons, L.M., Somoskövi, A., Gutierrez, C., Lee, E., Paramasivan, C.N., Abimiku, A., Spector, S., Roscigno, G. and Nkengasong, J. (2011) Laboratory Diagnosis of Tuberculosis in Resource-Poor Countries. Challenges and Opportunities. Clinical Microbiology Reviews, 24, 314-350. https://doi.org/10.1128/CMR.00059-10

Submit or recommend next manuscript to SCIRP and we will provide best service for you:

Accepting pre-submission inquiries through Email, Facebook, LinkedIn, Twitter, etc. A wide selection of journals (inclusive of 9 subjects, more than 200 journals)

Providing 24-hour high-quality service

User-friendly online submission system

Fair and swift peer-review system

Efficient typesetting and proofreading procedure

Display of the result of downloads and visits, as well as the number of cited articles

Maximum dissemination of your research work

Submit your manuscript at: http://papersubmission.scirp.org/

Or contact jtr@scirp.org 